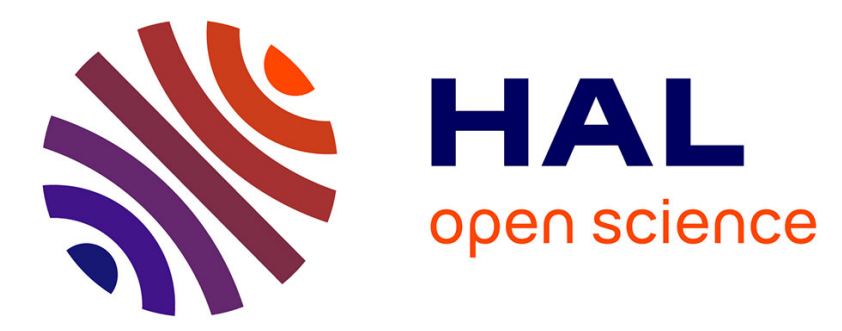

\title{
Very high cycle fatigue of a high strength steel under sea water corrosion: A strong corrosion and mechanical damage coupling
}

\author{
Ruben Perez-Mora, Thierry Palin-Luc, Claude Bathias, Paul C. Paris
}

\section{- To cite this version:}

Ruben Perez-Mora, Thierry Palin-Luc, Claude Bathias, Paul C. Paris. Very high cycle fatigue of a high strength steel under sea water corrosion: A strong corrosion and mechanical damage coupling. International Journal of Fatigue, 2015, 74, pp.156-165. 10.1016/j.ijfatigue.2015.01.004 hal-01110745

\author{
HAL Id: hal-01110745 \\ https://hal.science/hal-01110745
}

Submitted on 29 Jan 2015

HAL is a multi-disciplinary open access archive for the deposit and dissemination of scientific research documents, whether they are published or not. The documents may come from teaching and research institutions in France or abroad, or from public or private research centers.
L'archive ouverte pluridisciplinaire HAL, est destinée au dépôt et à la diffusion de documents scientifiques de niveau recherche, publiés ou non, émanant des établissements d'enseignement et de recherche français ou étrangers, des laboratoires publics ou privés. 


\title{
Very high cycle fatigue of a high strength steel under sea water corrosion: A strong corrosion and mechanical damage coupling
}

\author{
Ruben Pérez-Mora ${ }^{a}$, Thierry Palin-Luc ${ }^{\mathrm{b}, *}$, Claude Bathias ${ }^{\mathrm{a}}$, Paul C. Paris ${ }^{\mathrm{c}}$ \\ ${ }^{a}$ Universite Paris Ouest, LEME, 50 rue de Sevres, 92410 Ville d'Avray, France \\ ${ }^{\mathrm{b}}$ Arts et Metiers ParisTech, I2M, CNRS, Universite de Bordeaux, Esplanade des Arts et Metiers, 33405 Talence Cedex, France \\ ${ }^{c}$ Parks College of Engineering, Aviation and Technology, St. Louis University, St. Louis, MO 63103, USA
}

Keywords:

Gigacycle fatigue

Corrosion

Steel

Crack initiation

Crack growth

\begin{abstract}
A B S T R A C T
This paper is focused on the effect of sea water corrosion on the gigacycle fatigue strength of a martensitic-bainitic hot rolled steel R5 used for manufacturing off-shore mooring chains for petroleum platforms in the North Sea. Crack initiation fatigue tests in the regime of $10^{6}$ to $10^{10}$ cycles were carried out on smooth specimens under three different environment conditions: (i) without any corrosion (virgin state) in air, (ii) in air after pre-corrosion, and (iii) in-situ corrosion-fatigue under artificial sea water flow. A drastic effect of sea water corrosion was found: the median fatigue strength beyond $10^{8}$ cycles is divided by 5 compared to virgin state specimens. The crack initiation sites were corrosion pits caused by precorrosion or created during corrosion-fatigue under sea water flow. Furthermore some sub-surface and internal crack initiations were observed on specimens without any corrosion (virgin state). Crack propagation curves were obtained in mode I in air and under sea water flow. Calculation of the stress intensity factor at the tip of cracks emanating from hemispherical surface pits combined with the Paris-Hertzberg-Mc Clintock crack growth rate model showed that fatigue crack initiation period represents most of the fatigue life in the VHCF regime. Additional original experiments have shown physical evidences that the fatigue strength in the gigacycle regime under sea water flow is mainly governed by the corrosion process with a strong coupling between cyclic loading and corrosion.
\end{abstract}

\section{Introduction}

The mooring chains of off-shore petroleum platforms are designed for 30 years and loaded in fatigue in corrosive environment due to sea water. Because of the ocean waves (frequency varying between 0.1 and $1 \mathrm{~Hz}$ ) $24 \mathrm{~h}$ a day, the number of load cycles during 30 years is between $9.5 \times 10^{7}$ and $9.5 \times 10^{8}$ cycles that is in the gigacycle regime (more than $10^{8}$ cycles). This study is focused on the gigacycle fatigue strength of low alloy steel used for manufacturing such chains. The effect of pre-corrosion and real time corrosion conditions on the fatigue strength and crack growth rate are investigated. It has been demonstrated by many studies on steel and aluminum alloys in the gigacycle regime that there is no fatigue limit for such metals beyond $10^{7}$ cycles as was believed in the past $[1,2]$. Moreover, fatigue cracks initiate mainly at surface defects in the short fatigue life regime, but may shift to subsurface in the long life range [3]. Some other studies have shown that defects like non-metallic inclusions, pores [4] or pits [5-7] are

\footnotetext{
* Corresponding author.

E-mail address: thierry.palin-luc@ensam.eu (T. Palin-Luc).
}

the key factors that control the fatigue behavior of metals in very high cycle fatigue (VHCF) regime. On the other hand, some studies have been proving that crack initiation dominates the total fatigue life of iron alloys in gigacycle fatigue in air $[8,9]$. Furthermore, the influence of static deformation has been studied confirming that both passive and transpassive current densities on stainless steel reach a maximum in the course of growing plastic strain [10]. Other studies have investigated the dissolution under chemical products on stainless steel with active, passive and intermediate potentials where it is presumed that dissolution is enhanced during cyclic loading [11]. But the effect of aqueous corrosion on the fatigue strength with regard to crack initiation in the VHCF regime is not very much studied in literature [12]. In this regime the material is loaded in its elastic domain at the macroscopic scale. In this study the effect of sea water corrosion (under free potential) on the VHCF strength is studied.

After presenting the investigated material and the experimental conditions both for crack initiation and crack propagation tests, experimental results are presented and discussed with regard to SEM observations of the fracture surface. It is shown that a drastic effect of sea water corrosion decreases the fatigue strength of the 


\begin{tabular}{|c|c|c|c|}
\hline \multicolumn{4}{|c|}{ Nomenclature } \\
\hline$a$ & crack length & $N_{a o-a i}$ & number of cycles of the small crack growth period \\
\hline$a_{\text {int }}$ & crack length at initiation & $N_{\text {aint-ao }}$ & number of cycles of the short crack growth period \\
\hline$a_{0}$ & crack length at the corner of the crack growth curve cor- & $R$ & radius of hemispherical surface defect \\
\hline$b$ & $\begin{array}{l}\text { responding to the threshold } \Delta K_{\text {th }} \\
\text { Burger vector }\end{array}$ & $U_{0}$ & $\begin{array}{l}\text { displacement amplitude at the extremity of the speci- } \\
\text { men }\end{array}$ \\
\hline E & Young's modulus & $w$ & width of the crack growth specimen \\
\hline$N_{f}$ & total number of cycles to failure including initiation and & & Poisson ratio \\
\hline $\begin{array}{l}N_{\text {prop }} \\
N_{\text {ai-a }}\end{array}$ & $\begin{array}{l}\text { propagation periods } \\
\text { number of cycles of the crack propagation period } \\
\text { number of cycles of the long crack growth period }\end{array}$ & $\begin{array}{l}\Delta K \\
\Delta K_{\mathrm{th}} \\
\sigma_{a}\end{array}$ & $\begin{array}{l}\text { range of the stress intensity factor } \\
\text { range of the stress intensity factor at the threshold } \\
\text { stress amplitude }\end{array}$ \\
\hline
\end{tabular}

steel under sea water flow. The assessment of the crack growth helps us to show that crack initiation dominates the total fatigue life in the gigacycle regime. Furthermore, additional experiments allow the authors to show experimental evidences of coupling between corrosion and cyclic loading even under ultrasonic loading frequency.

\section{Material and experimental conditions}

The material studied hereafter is a non-standard hot rolled low alloy steel grade (named R5 according to the International Classification Societies of Off-shore Systems) with a typical fine grain microstructure, composed by tempered martensite and bainite, as shown in Fig. 1. Its chemical composition is shown in Table 1. This steel is used after a double quenching in water, a first period at $920^{\circ} \mathrm{C}$ and a second period at $880^{\circ} \mathrm{C}$ and then tempering at $650{ }^{\circ} \mathrm{C}$ with water cooling. After this heat treatment its mechanical properties are: hardness $317 \mathrm{HB}$, yield strength $970 \mathrm{MPa}$, ultimate tensile strength UTS $=1018 \mathrm{MPa}$, Young modulus $E=211 \mathrm{GPa}$ under monotonic quasi-static tension. It has to be noticed that this steel is vacuum degassed with low hydrogen content (1 ppm maximum in the liquid steel after the vacuum treatment). Furthermore, very low non-metallic inclusions are present in this steel (see details in [12]).

\subsection{Fatigue test conditions and specimen geometry}

\subsubsection{Testing machine and specimen geometry}

All the fatigue tests (crack initiation and crack growth) presented hereafter were carried out with an ultrasonic fatigue testing

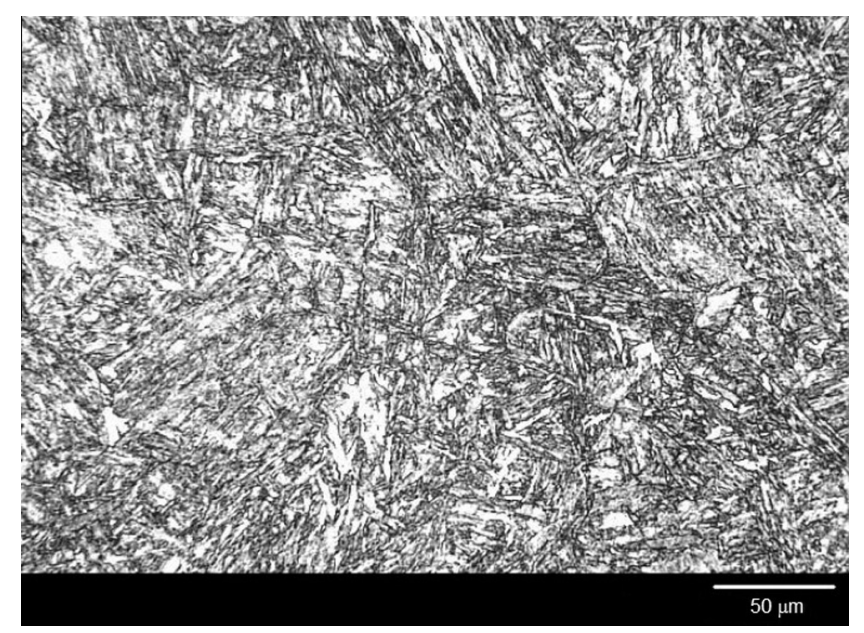

Fig. 1. R5 steel microstructure (after Nital etching 2\%).
Table 1

Composition of R5 steel (wt\%, Fe balance).

\begin{tabular}{llllllllll}
\hline $\mathrm{C}$ & $\mathrm{Mn}$ & $\mathrm{Si}$ & $\mathrm{P}$ & $\mathrm{S}$ & $\mathrm{Cr}$ & $\mathrm{Ni}$ & $\mathrm{Mo}$ & $\mathrm{V}$ & $\mathrm{O}$ \\
\hline 0.22 & 1.22 & 0.3 & 0.009 & 0.003 & 1.07 & 1.07 & 0.5 & 0.09 & $12 \mathrm{ppm}$ \\
\hline
\end{tabular}

machine [1] operating continuously at $20 \mathrm{kHz}$ (no pulse loading) under fully reversed tension $(R=-1)$ (see $[1,12]$ for details). Fig. 2 shows the dimensions of the two types of specimens used for (a) VHCF crack initiation tests and (b) fatigue crack growth (FCG) tests. The geometry of the FCG specimens was designed according to the works of Wu [13] and Sun [14]. The crack growth was measured with an optical binocular microscope equipped with a digital camera; this set up has a maximum magnification $\times 200$ and a resolution of $0.5 \mu \mathrm{m}$. The roughness of the tested area of the VHCF specimens was $R a=0.6 \mu \mathrm{m}$; additionally a few specimens with a lower arithmetic roughness $(R a=0.1 \mu \mathrm{m})$ were tested too for investigating the effect of roughness. The VHCF specimens were tested under three different conditions: (i) without any corrosion (virgin state), (ii) after pre-corrosion and (iii) under real time artificial sea water flow.

All the VHCF tests were calibrated by using a wide band $(100 \mathrm{kHz})$ strain gauge conditioner and a longitudinal strain gauge glued on the specimen surface. Such calibration allows the authors to be certain of the local strain (elastic stress) amplitude and mean value in the narrowest cross section of the specimen. These tests were carried out until a decrease of the resonance frequency of $0.5 \mathrm{kHz}$ that indicates the presence of a macrocrack.

\subsubsection{Corrosion of the specimens}

The pre-corrosion of the specimens was done according to the ASTM G85 standard: $600 \mathrm{~h}$ in a salt fog corrosion chamber under temperature and humidity control $\left(35^{\circ} \mathrm{C}\right.$ with $95 \%$ of humidity). The salt solution contains $5 \%$ of $\mathrm{NaCl}$, its $\mathrm{pH}$ was 6.6 and it was applied in the chamber with a flow rate of $1.52 \mathrm{ml} / \mathrm{h}$. After the pre-corrosion process the specimens were first chemically cleaned and then cleaned with emery paper to remove the oxide layer. Many corrosion pits were created by the salt fog (Fig. 3) which diameter is between 30 and $80 \mu \mathrm{m}$. These pits have hemispherical shape and their depth can be compared with their radius. Comparing this dimension to prior austenite grain size, the pits are in between one and two times the size of the prior austenite grains.

To carry out VHCF tests in sea water environment a special corrosion cell was designed (see [12] for details). To avoid any cavitation it was decided to test the specimens under sea water flow without immersion. This is representative of the splash zone of the mooring chains. To do that a peristaltic pump creates a flow of sea water $(100 \mathrm{ml} / \mathrm{min})$ on two opposite sides of the specimen surface in the tested area (diameter $3 \mathrm{~mm}$ ). The sea water used was the A3 standard synthetic sea water; its chemical composition 


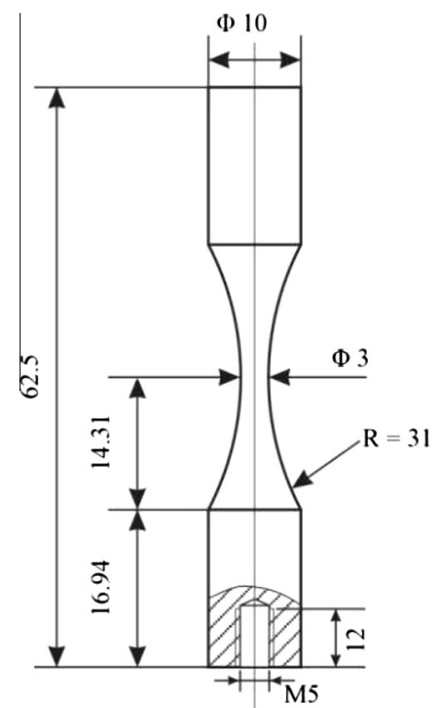

(a)

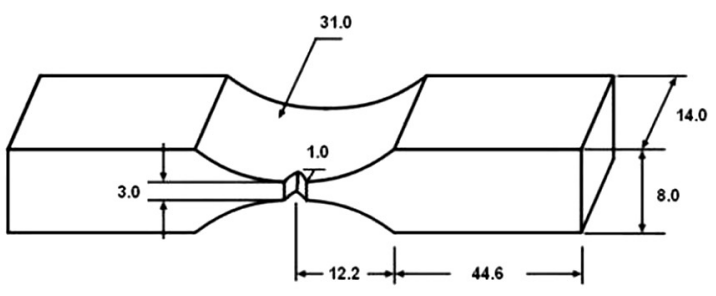

$60^{\circ}$

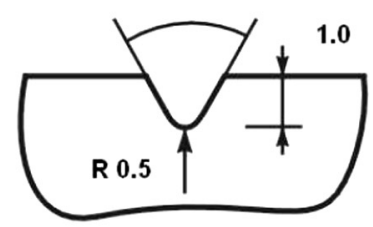

(b)

Fig. 2. Specimen geometry for (a) VHCF tests, $K t=1.02$, (b) crack growth tests (dimensions in $\mathrm{mm}$ ).
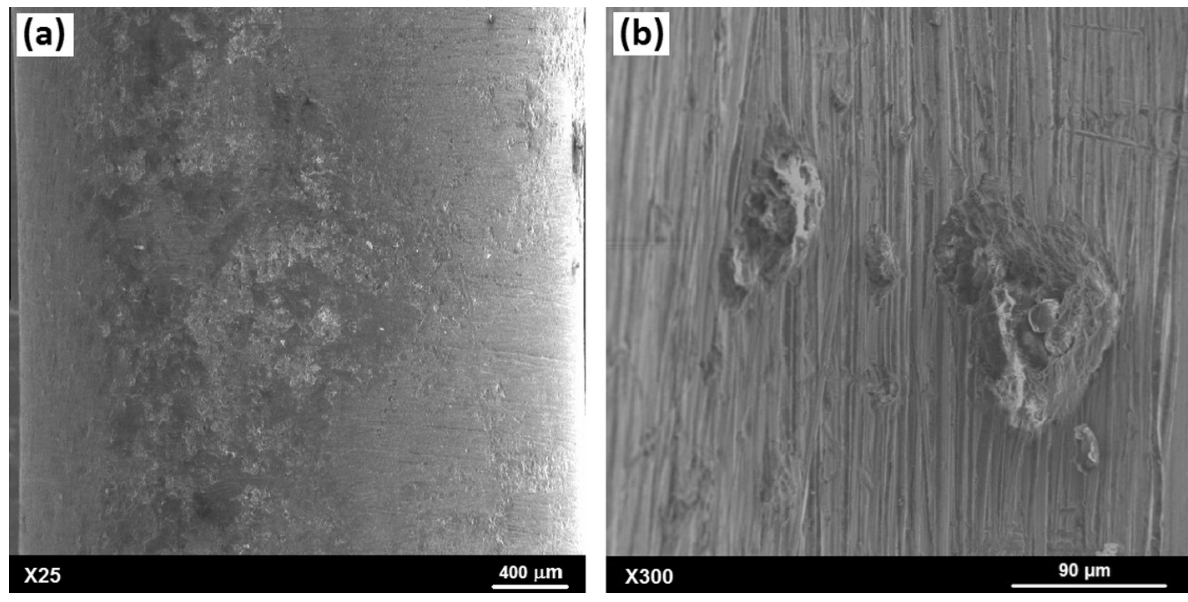

Fig. 3. (a) Surface of a specimen after pre-corrosion in the salt fog chamber, (b) zoom on a corrosion pit.

(in weight) is: $24.53 \% \mathrm{NaCl}, 5.2 \% \mathrm{MgCl}_{2}, 4.09 \% \mathrm{Na}_{2} \mathrm{SO}_{4}, 1.16 \% \mathrm{CaCl}_{2}$, $0.695 \% \mathrm{KCl}$ and $0.201 \% \mathrm{NaHCO}_{3}$. The $\mathrm{pH}$ of this solution is 6.6 and specimens were tested under free potential. The temperature of the sea water was $20-25^{\circ} \mathrm{C}$ (room temperature).

\subsubsection{Fatigue crack growth tests}

Fatigue crack growth tests were carried out under fully reversed tension $(R=-1)$ in mode I following a similar methodology than prescribed in ASTM E647 standard. Since with the ultrasonic fatigue testing device the specimen is loaded under displacement control, the range of the mode I stress intensity factor $\Delta K$ was computed according to Refs. $[13,14]$ :

$\Delta K=U_{o}\left(\frac{E}{1-v^{2}}\right) \sqrt{\frac{\pi}{a}} Y(a / w)$

where

$Y(a / w)=0.635(a / w)+1.731(a / w)^{2}-3.979(a / w)^{3}+1.963(a / w)^{4}$.

$U_{0}$ is the displacement amplitude imposed at the top of the specimen by the horn of the ultrasonic machine, $E$ is the dynamic modulus and $v$ is the Poisson ratio of the material, $Y(a / w)$ is a function depending on the specimen geometry, $w$ is the width of the specimen and $a$ is the crack length measured from the specimen surface (i.e. including the notch depth of $1 \mathrm{~mm}$ ). A natural precrack of $0.5 \mathrm{~mm}$ (from the notch root) is developed in tensioncompression before the crack growth test itself. For the crack growth tests carried out in sea water the pre-crack was done in air and then the specimen with the natural crack at the notch was tested.

\section{Experimental results and discussion}

\subsection{Fatigue crack initiation tests}

Fig. 4 shows the S-N curves up to fracture. The scatter of the fatigue strength is larger for the pre-corroded specimens than for the virgin ones (45.7 and $18.2 \mathrm{MPa}$ respectively). However a decreasing of around $50 \mathrm{MPa}$ of the fatigue strength for the specimens with pre-corrosion is observed compared to the specimens without any corrosion. There is a drastic effect of sea water flow on the fatigue strength of the R5 steel in the VHCF fatigue regime. Indeed, for the specimens tested under sea water flow, the fatigue strength at $10^{7}$ cycles is around $300 \mathrm{MPa}$, not far from the value for 


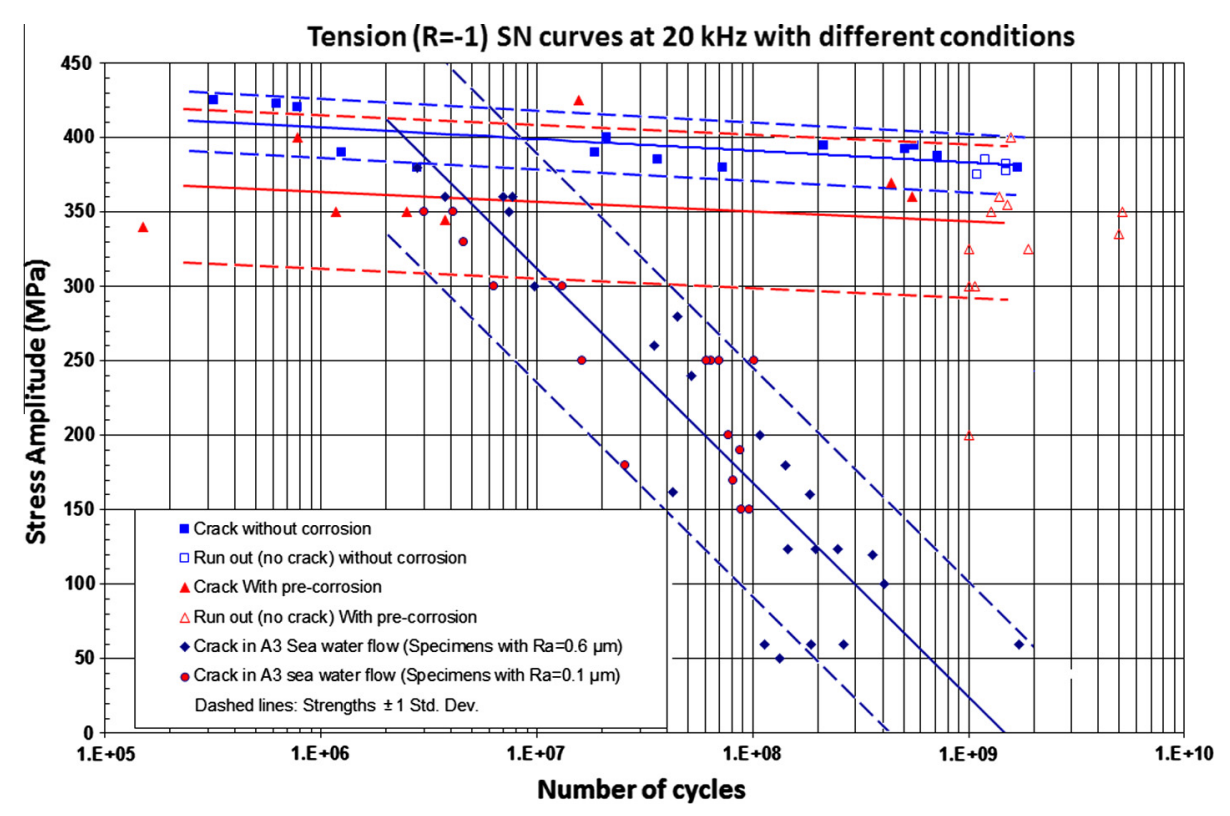

Fig. 4. S-N curves of the R5 steel under fully reversed tension at $20 \mathrm{kHz}$.

pre-corroded specimens ( $360 \mathrm{MPa}$ ), but for $3 \times 10^{8}$ cycles the fatigue strength is around $100 \mathrm{MPa}$ only. That is a decrease of $74 \%$ compared to the non-corroded specimens (390 MPa) and a decrease of $71 \%$ compared to the pre-corroded ones (350 MPa). This shows that stopping the fatigue tests at $10^{7}$ cycles and then extrapolating the $\mathrm{S}-\mathrm{N}$ curve may lead to a large overestimation of the corrosion-fatigue resistance.

The fatigue tests were carried out at $20 \mathrm{kHz}$ under corrosive environment and may be seen first as non-representative experiments because of the high loading frequency compared with the characteristic time of the corrosion process. However, it has been shown by El May et al. [18] that the fatigue strength in tension of a martensitic stainless steel in the high cycle fatigue regime (at $10^{7}$ cycles) is significantly reduced by corrosion in $0.1 \mathrm{M} \mathrm{NaCl}$ aqueous solution even at $120 \mathrm{~Hz}$. Furthermore, these authors have shown that there is no significant frequency effect between 10 and $120 \mathrm{~Hz}$ between $10^{5}$ and $10^{7}$ cycles.

Our fatigue corrosion tests results (Fig. 4) show that the S-N curve of specimens tested under sea water flow crosses (around $2-3 \times 10^{6}$ cycles) the S-N curve of virgin specimens (tested in air without any corrosion). This is not in agreement with a frequency effect but with the fact that a number of cyclic reversals $(2 \times \mathrm{N})$ are needed to create corrosion fatigue defects and coupling as proposed in [18]. This will be discussed later in this paper.

\subsection{SEM observation of the fracture surfaces}

On virgin specimens, even if some unusual internal crack initiations were observed (Fig. 5), most of the fatigue cracks initiated at the specimen surface over the cycle range $\left(10^{6}-10^{9}\right.$ cycles). But for this set of specimens no defect was observed in the crack initiation area. Surface corrosion pits were the origins of the cracks for both pre-corroded specimens and specimens tested under sea water flow (Figs. 6 and 7). For the specimens tested under sea water flow the cracks initiated all around the specimen surface due to several large corrosion pits. The size of the pits depends on the time (i.e. the number of cycles); their diameter is smaller on the precorroded specimens $(30-80 \mu \mathrm{m})$ than under sea water flow (50-300 $\mu \mathrm{m}$ ) (Figs. 6 and 7). Furthermore, a lot of small cracks, perpendicular to the loading direction (mode I), were observed at the surface of the specimens tested under sea water flow, as shown in Fig. 7(c); whereas such small cracks were not observed on both virgin and pre-corroded specimens. This is characteristic of a corrosion/cyclic loading interaction.

Since a significant decrease of the fatigue strength has been observed due to corrosion pits (seen as geometrical defects), it is important to determine if the crack propagation stage dominates the total fatigue life.

\subsection{Assessment of the crack initiation and propagation duration}

The experimental $\frac{d a}{d N}=f(\Delta K)$ curve is shown in Annex 1 ; this is re-plotted as $\frac{d a}{d N}=f\left(\frac{\Delta K_{\text {eff }}}{E \sqrt{b}}\right)$ curve in Fig. 8. This shows that in air the mode I stress intensity factor threshold for R5 steel is around 3.3 MPa $\sqrt{ } \mathrm{m}$ for $(R=-1)$. This value is between 2 and $10 \mathrm{MPa} \sqrt{ } \mathrm{m}$ as reported for steels in Refs. [22,23]. As usual the crack growth rate is faster under sea water flow than in air [15]. The fatigue crack propagation duration was assessed according to the work of Paris et al. [8,9], based on the Paris-Hertzberg-Mc Clintock crack growth model: $\frac{d a}{d N}=b\left(\frac{\Delta K_{\text {eff }}}{E \sqrt{b}}\right)^{3}$ and $\left(\frac{K_{\text {eff }}}{E \sqrt{b}}\right)=1$ at the corner (intersection between the Paris line and the threshold line), where $E$ is the elastic modulus and $b$ is the Burger's vector. The good agreement of this equation with our experimental data and $b=0.285 \mathrm{~nm}$ was shown in [12]. Since in our experiments at $20 \mathrm{kHz}$ the measurement of $K_{o p}$ is not possible, in first approximation $\Delta K_{\mathrm{eff}} \approx K_{\max }$ was assumed. We do not know if $K_{o p}$ is frequency dependent that is why its value was not measured at low frequency and assumed to be the same at $20 \mathrm{kHz}$. Furthermore the authors assume that water present into the crack does not modify the value of the stress intensity factor. It is clear in Fig. 8 that since the crack growth rate in sea water is higher than in air; computing the crack growth duration based on the crack growth curve in air may only underestimate this duration.

To assess this duration, a corrosion pit was not modeled as a crack-like defect but it was modeled as a hemispherical surface defect of radius $R$ with a semi-circular crack emanating from it. The existence of these hemispherical pits was observed by scanning electron microscopy on the surface of different specimens with pre-corrosion in salt fog chamber (Fig. 3) and after corrosion 

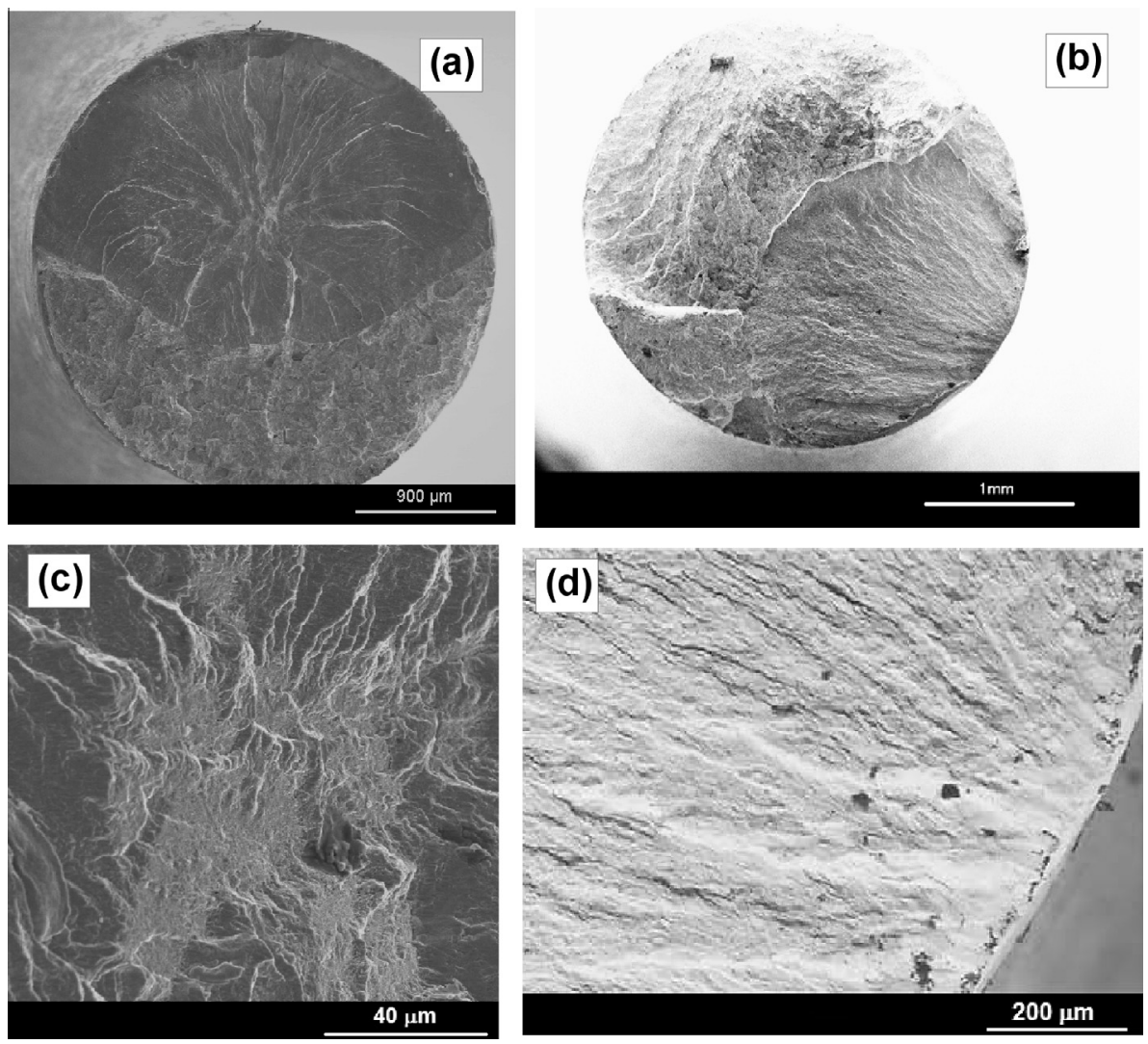

Fig. 5. Fracture surface of R5 steel virgin specimens (a, c) internal crack initiation $\sigma_{a}=380 \mathrm{MPa}, N_{f}=2.78 \times 10^{6}$ cycles, (b, d) surface crack initiation $\sigma_{a}=395 \mathrm{MPa}$, $N_{f}=5.61 \times 10^{8}$ cycles.
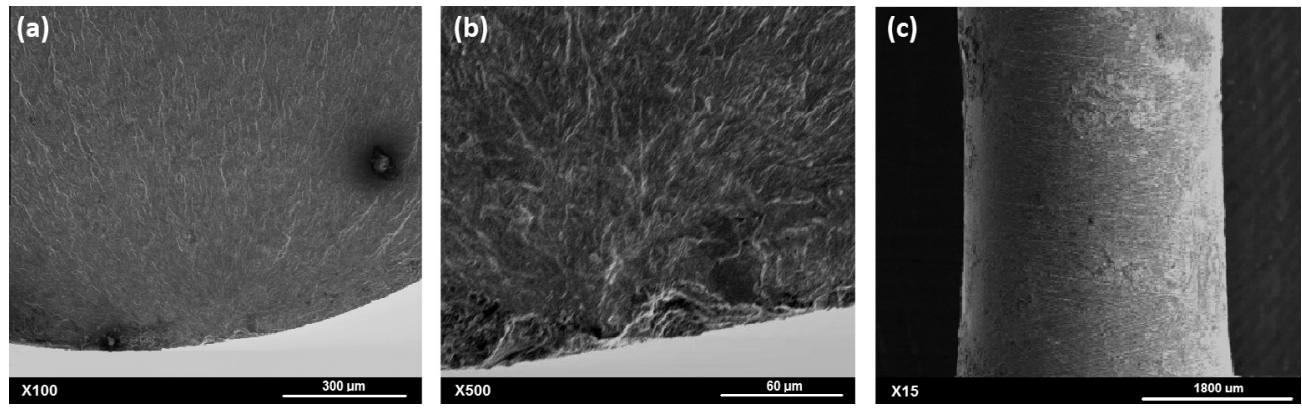

Fig. 6. Specimen with pre-corrosion, $\sigma_{a}=425 \mathrm{MPa}, N_{f}=1.6 \times 10^{7}$ cycles.
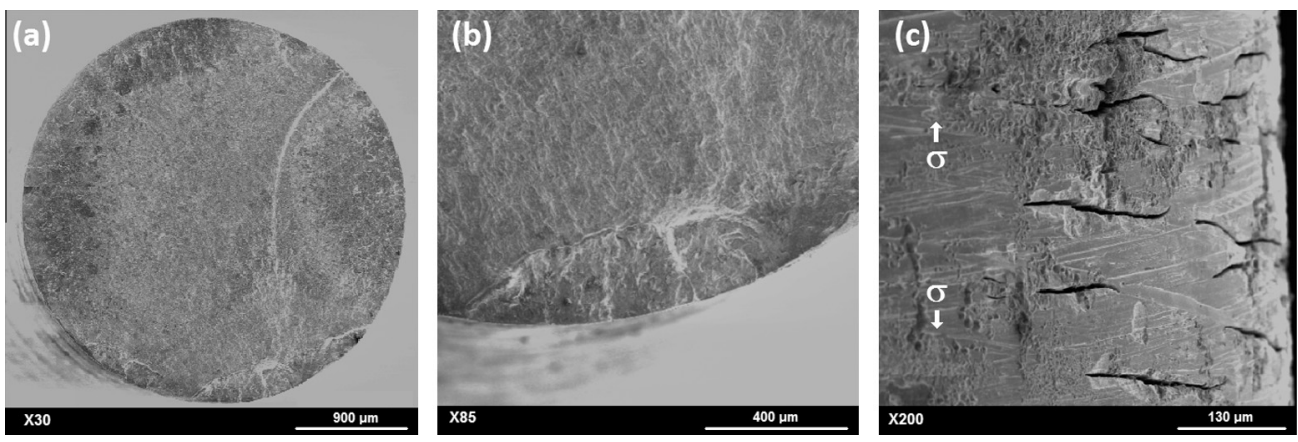

Fig. 7. Specimen tested under sea water flow, $\sigma_{a}=240 \mathrm{MPa}, N_{f}=5.2 \times 10^{7}$ cycles. 


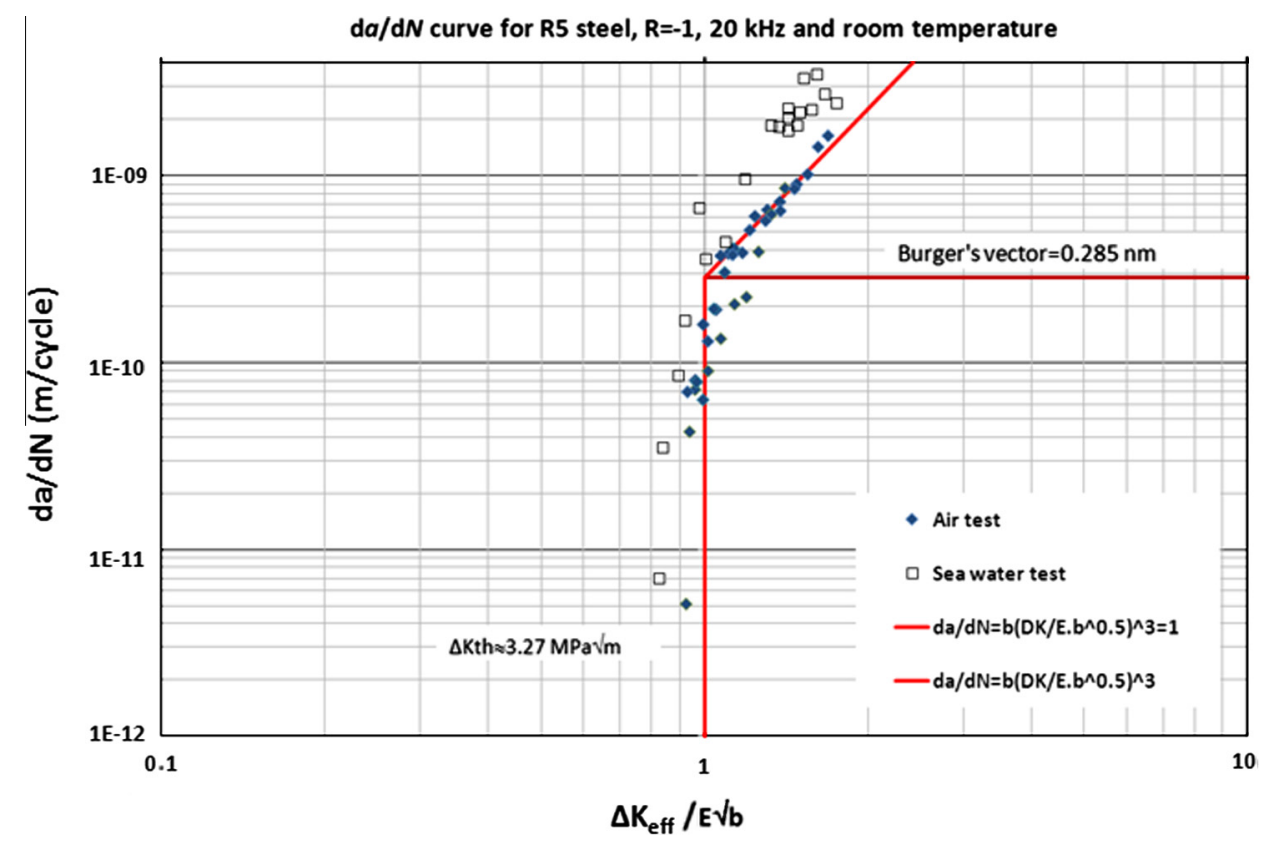

Fig. 8. $\frac{\mathrm{d} a}{\mathrm{~d} N}=f\left(\frac{\Delta K_{\mathrm{eff}}}{E \sqrt{b}}\right)$ curve in mode I for the R5 steel $(R=-1)$, in air and under sea water flow at room temperature.

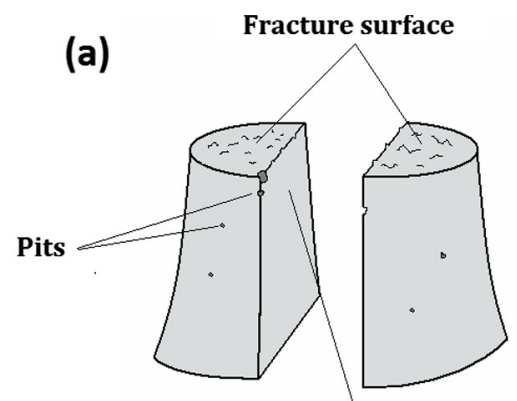

Observed area
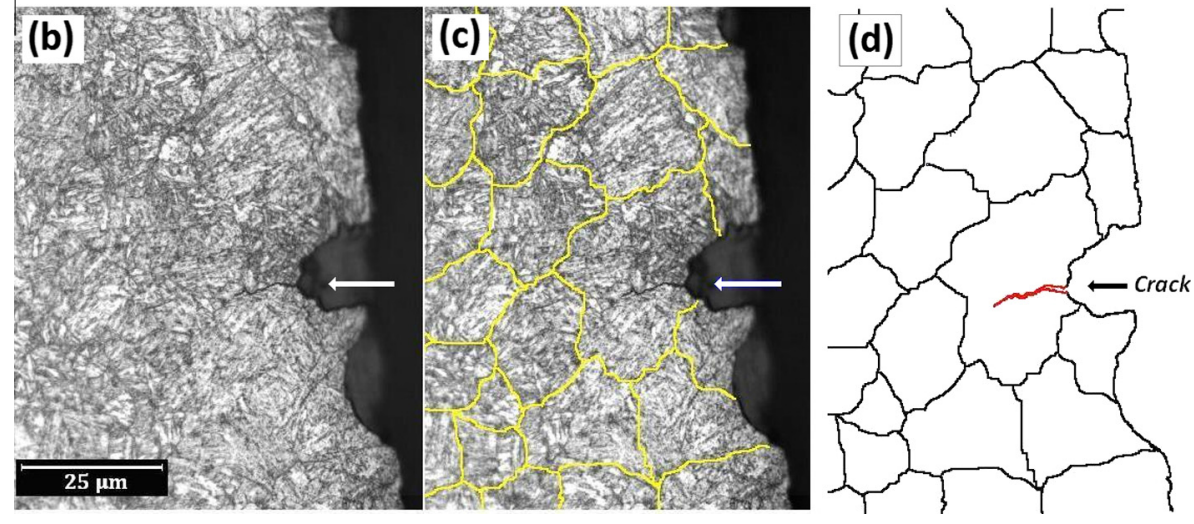

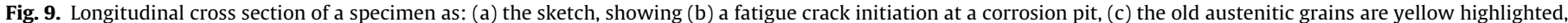
(d) illustration of the short fatigue crack and the grain boundaries.

under A3 sea water flow (Fig. 7). The longitudinal cross section of a pre-corroded specimen (after $4.37 \times 10^{8}$ cycles under a stress amplitude of $370 \mathrm{MPa}$ ) close to the fracture surface was observed as illustrated in Fig. 9(a) and (b). This shows a short crack initiated at a corrosion pit. Based on this observation, an initial fatigue crack of depth $a_{i n t}$ emanating from the surface of the hemispherical pit and perpendicular to the loading direction due to intercristalline corrosion cracking was assumed. The length of the initial short crack emanating from hemispherical defects was assumed to be $a_{\text {int }} \sim 10 \mu \mathrm{m}$ (Fig. 9(c) and (d).

According to the asymptotic approximation proposed by Paris et al. [16] (with details in [24]) the crack tip stress intensity factor in mode I is: $K_{I}=\sigma Y(x / v) \sqrt{\pi a}$, where $x=a / R, v$ is the Poisson ratio, and $Y(x, v)$ is a geometry dependent function for a penny shape crack emanating from hemispherical surface crack [16]: 
$Y(x / v)=1.015\left[A(v)+B(v)\left(\frac{x}{1+x}\right)+C(v)\left(\frac{x}{1+x}\right)^{2}+D(v)\left(\frac{x}{1+x}\right)^{3}\right]$

with $A(v)=1.683+\frac{3.336}{7-5 v}, \quad B(v)=-1.025-\frac{12.3}{7-5 v}, \quad C(v)=-1.089+$ $\frac{14.5}{7-5,}, D(v)=1.068-\frac{5.568}{7-5 v^{\circ}}$

Let us note that we do not try to calculate the lifetime of the specimen, but the number of cycles of the crack propagation period, going back from the total number of load cycles (at rupture). It was assumed that the propagation of the fatigue crack is divided in three stages so that $N_{\text {Prop }}=N_{a_{\text {int }}-a_{0}}+N_{a_{0}-a_{i}}+N_{a_{i}-a}$. There is first crack initiation during $N_{a_{\text {int }}-a_{0}}$ cycles, from $a_{\text {int }}$ to the crack size $a_{0}$ ( $a_{0}$ corresponds to the threshold value of the stress intensity range $\left.\Delta K_{\mathrm{th}}\right)$. Then, there is the small crack propagation period $N_{a_{0}-a_{i}}$ cycles, from $a_{0}$ to the crack size $a_{i}$, and finaly a long crack propagation $N_{a_{i}-a}$ cycles, from $a_{i}$ to the final crack size $a$ (observed on the fracture surface of the specimen). With these three different regimes [12] the initiation regime and the quick propagation of small crack compared to long crack were considered. $\alpha$ is the exponent which defines the slope of the threshold curve, $d a / d N=b(a)$ $\left.a_{0}\right)^{\alpha / 2}$. The detailed equations are given in [12], they were applied to our data assuming that $a_{0}$ is corresponding to the corner for which $d a / d N=b$ (in such case it means a crack propagates with a speed equal to one Burger vector per cycle, $d a / d N=b$ per cycle).

Two cases are shown in Table 2 with two experimental total fatigue lives $N_{\text {exp }}$; several additional cases are detailed in [12]. In the first case $99.1 \%$ of the fatigue life is due to initiation. For the second case, $96 \%$ of the fatigue life was consumed by the initiation phase. Furthermore, it has been shown in [12] that with a high value of $\alpha$ and large $a_{\text {int }} / a_{0}$ one obtains similar $N_{\text {Total }}$ results than with a low $\alpha$ and small $a_{\text {int }} / a_{0}$, this is because a higher $\alpha$ means that crack does not grow as far due to the slope of the $d a / d N$ curve in the threshold region, then $a_{\text {int }} / a_{0}$ must be larger, and with a lower $\alpha$, $a_{\text {int }} / a_{0}$ must be smaller.

These calculations show that total lifetime is dominated by two phenomena: the cyclic loading assisted corrosion pitting and the crack initiation regime for creating the crack emanating from the pit. Let us recall that even if our calculations were carried out by using the crack growth curve in air, the conclusion is still valid because the crack growth rate for the R5 steel under sea water flow is higher than in air as shown in Fig. 8 and as usually reported in literature [15]. Furthermore it has to be noticed that the aim of this study is not to propose a pit growth model. Basically the aim of this study is to quantify the effect of corrosion on the VHCF strength, and to determine which phenomenon is governing corrosion fatigue under very low stress strain amplitude leading to a very high number of load cycles. Is it the corrosion process, fatigue crack initiation or propagation, or a coupling between corrosion and mechanical damage due to cyclic loading (i.e. fatigue)?

According to the authors there is actually no model that is able, in VHCF regime (that means under very low stress strain amplitudes), to model the effect of corrosion fatigue on both the initiation of pits and the crack growth emanating from them. Additionally, there are a few studies only dealing with corrosion fatigue in metals in the very high cycle fatigue regime, most of the corrosion fatigue papers are in the low cycle fatigue regime. In that case, the phenomena are different because of macroscopic cyclic plastic strains. The aim of the crack growth calculations presented before is not to compute with a high accuracy the propagation duration of the microstructurally short crack emanating from the pit, but to assess the duration of the crack growth period including initiation, small and long crack growth. Even if the Paris-Hertzberg-Mc Clintok model $[8,27,28]$ is not a microstructural fracture mechanics model, it takes into account with a phenomenological approach the crack growth rate differences between long crack, physically small crack and crack initiation. It has been already applied in literature to assess the crack propagation duration $[9,25]$. And if linear elastic fracture mechanics is not theoretically applicable for microstructurally short crack growth several empirical equations give good assessment for the key parameters of short crack growth as proposed for instance by Murakami [26].

Since previous calculations show that the fatigue life is dominated by the crack initiation regime even in corrosive environment, additional experiments have been carried out to try to understand why this initiation period is significantly affected by sea water flow.

\subsection{Additional experiments and discussion about the coupling between cyclic loading and corrosion}

To complete the previous tests an ultrasonic fatigue test has been carried out on a cylindrical specimen under see water flow. Since during an ultrasonic fatigue test a stationary wave is applied on the specimen, all along this cylinder different stress amplitudes are applied at each point [17].

Fig. 10(b) shows the distribution of the stress amplitude along the cylindrical specimen loaded in its central part with a stress amplitude of $120 \mathrm{MPa}$ (highest value all along the specimen). This corresponds to a mean fatigue life of $2 \times 10^{8}$ cycles according to the results of Fig. 4. For observation, the specimen surface was divided in 13 zones of around $1 \mathrm{~cm}$ long. During a single test each zone was submitted to different stress amplitudes. By testing such a cylinder under sea water flow as shown in Fig. 10(a), observation of the damaged areas allowed us to investigate the link between the stress amplitude and the damage due to the in-situ corrosion-fatigue process. The cylindrical specimen failed after $7.37 \times 10^{7}$ cycles.

Microscopic observations of the cylinder surface showed that R5 steel was damaged by corrosion-fatigue in the areas where the stress amplitude was higher than $56 \mathrm{MPa}$ (Fig. 10(c) shows corrosion pitting in a zone loaded around $115 \mathrm{MPa}$ ). Few corrosion traces only was observed where the stress amplitude was smaller (Fig. 10(d)). The final fracture occurred where the stress amplitude was between 112 and $120 \mathrm{MPa}$ whereas the SN curves in Fig. 4 show that below around $350 \mathrm{MPa}$ without any sea water flow there

Table 2

Hemispherical surface crack growth vs. experimental fatigue life, for $x=3$, and different $a_{i n t} / a_{0}$ ratios.

\begin{tabular}{|c|c|c|c|c|c|}
\hline$\alpha$ & aint/a0 & $N_{\text {aint-a0 }}$ & $N_{a 0-a \mathrm{i}}$ & $N_{a i-a}$ & $N_{\text {Prop }}$ (cycles) \\
\hline \multicolumn{6}{|c|}{ Case 1: $a_{0}=9.32 \mu \mathrm{m}, \sigma_{a}=360 \mathrm{MPa}, R=48 \mu \mathrm{m}, a=2.4 \mathrm{~mm}, N_{\text {exp }}=5.5 \times 10^{8}$ cycles on a pre-corroded specimen } \\
\hline \multirow[t]{3}{*}{100} & 0.9 & 115,801 & 44,151 & $4,507,080$ & $4,667,032$ \\
\hline & 0.94 & 13,163 & & & $4,564,394$ \\
\hline & 0.97 & 2,300 & & & $4,553,531$ \\
\hline \multicolumn{6}{|c|}{ Case 2: $a_{0}=13.01 \mu \mathrm{m}, \sigma_{a}=200 \mathrm{MPa}, R=290 \mu \mathrm{m}, a=2.81 \mathrm{~mm}, N_{\text {exp }}=1.08 \times 10^{8}$ cycles on specimen tested under sea water flow } \\
\hline \multirow[t]{3}{*}{100} & 0.9 & 286,158 & 67,524 & $3,624,895$ & $3,978,576$ \\
\hline & 0.94 & 32,528 & & & $3,724,946$ \\
\hline & 0.97 & 5,683 & & & $3,698,101$ \\
\hline
\end{tabular}




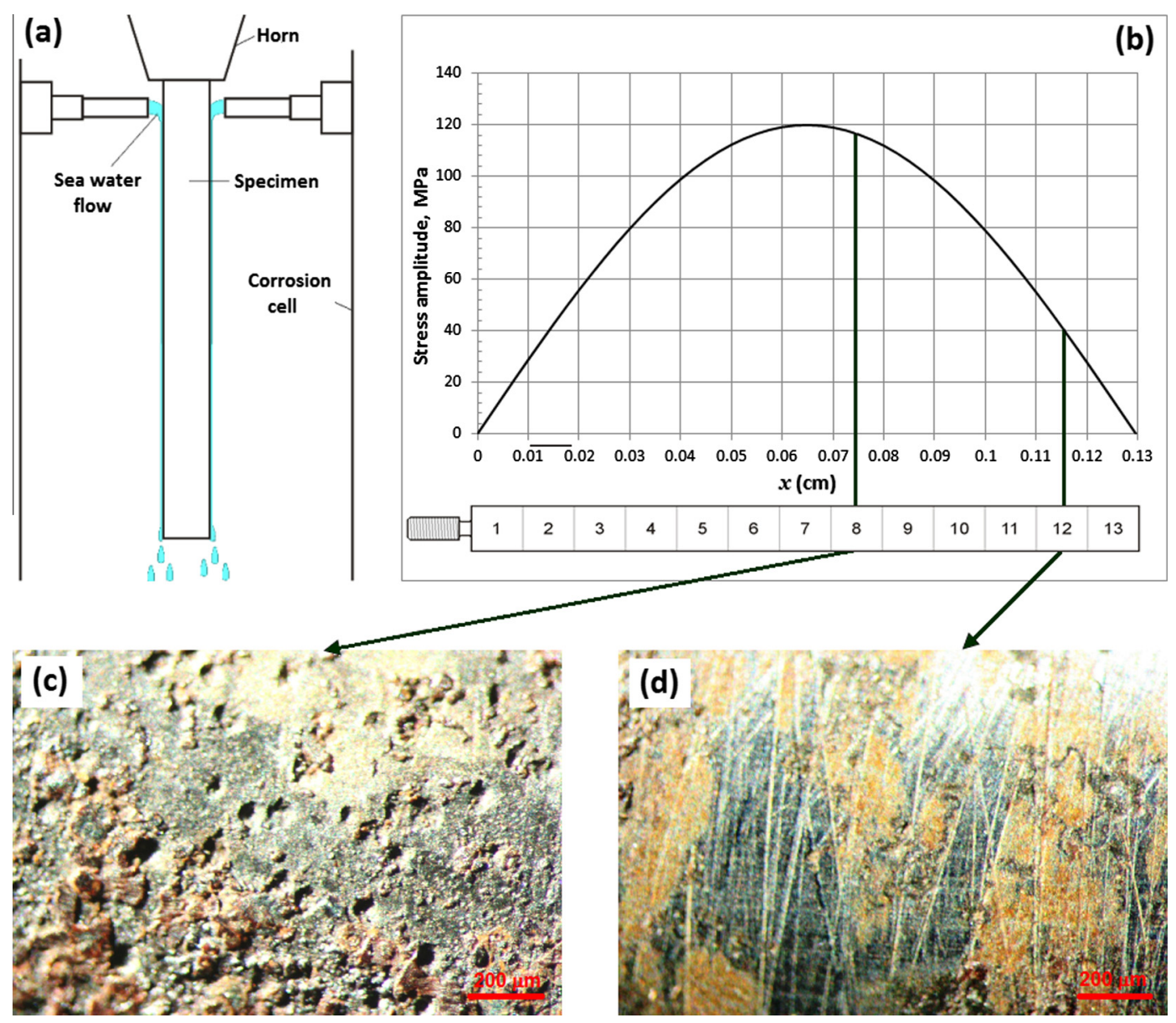

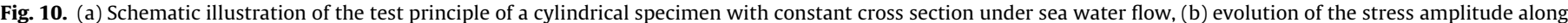

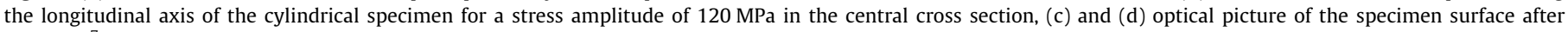
$7.37 \times 10^{7}$ cycles in area 8 and area 12 loaded at different stress amplitudes.

was no failure after $2 \times 10^{8}$ cycles. This shows an experimental evidence of the strong coupling between the corrosion process and cyclic loading in a wide range of stress amplitudes even at ultrasonic frequency $(20 \mathrm{kHz})$.

Furthermore, three additional tests were carried out on VHCF specimens under the same conditions than all the other tests but, without any cyclic loading. Only the sea water flow was applied on the specimen surface with the same flow rate than for the tests with cyclic loading. The aim of these tests was to quantify the corrosion damage (alone) after the same duration than $10^{7}$ cycles $(8 \mathrm{~min} 20 \mathrm{~s}$ at $20 \mathrm{kHz}), 10^{8}$ cycles $(1 \mathrm{~h} 23 \mathrm{~min} 20 \mathrm{~s}$ at $20 \mathrm{kHz}$ ) and $10^{9}$ cycles $(13 \mathrm{~h} 53 \mathrm{~min} 20 \mathrm{~s}$ at $20 \mathrm{kHz}$ ). No corrosion trace was observed by SEM after 8 mn20s. After 1 h 23 min 20 s only a few traces of corrosion appear but no pits were observed. Corrosion pits were observed at the specimen surface after $13 \mathrm{~h} 53 \mathrm{mn} 20 \mathrm{~s}$. The typical size of these pits was varying between 30 and $60 \mu \mathrm{m}$ (Fig. 11) this is significantly smaller than under simultaneous cyclic loading and sea water flow (Fig. 7). The same pit size was observed under sea water flow with a stress amplitude of $240 \mathrm{MPa}$ after $5 \times 10^{7}$ cycles. This corresponds to $42 \mathrm{mn}$ only at $20 \mathrm{kHz}$ ! This confirms that there is a coupling between corrosion and cyclic loading.

Because of such coupling, the question of the roughness effect occurred. Complementary fatigue tests were carried out under
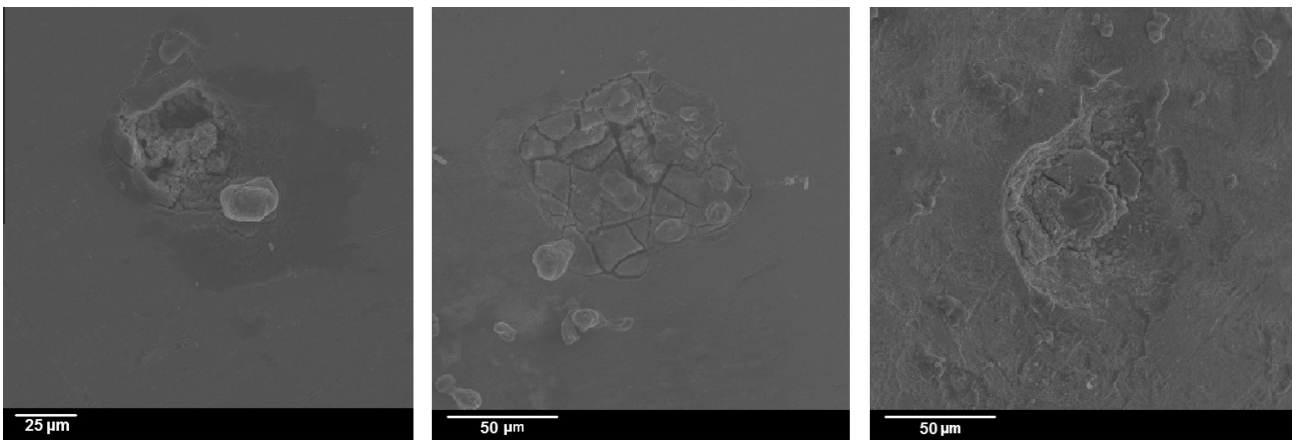

Fig. 11. Corrosion pits at the surface of a specimen under sea water flow during $13 \mathrm{~h} 53 \mathrm{~min} 20 \mathrm{~s}$ without any cyclic loading. 


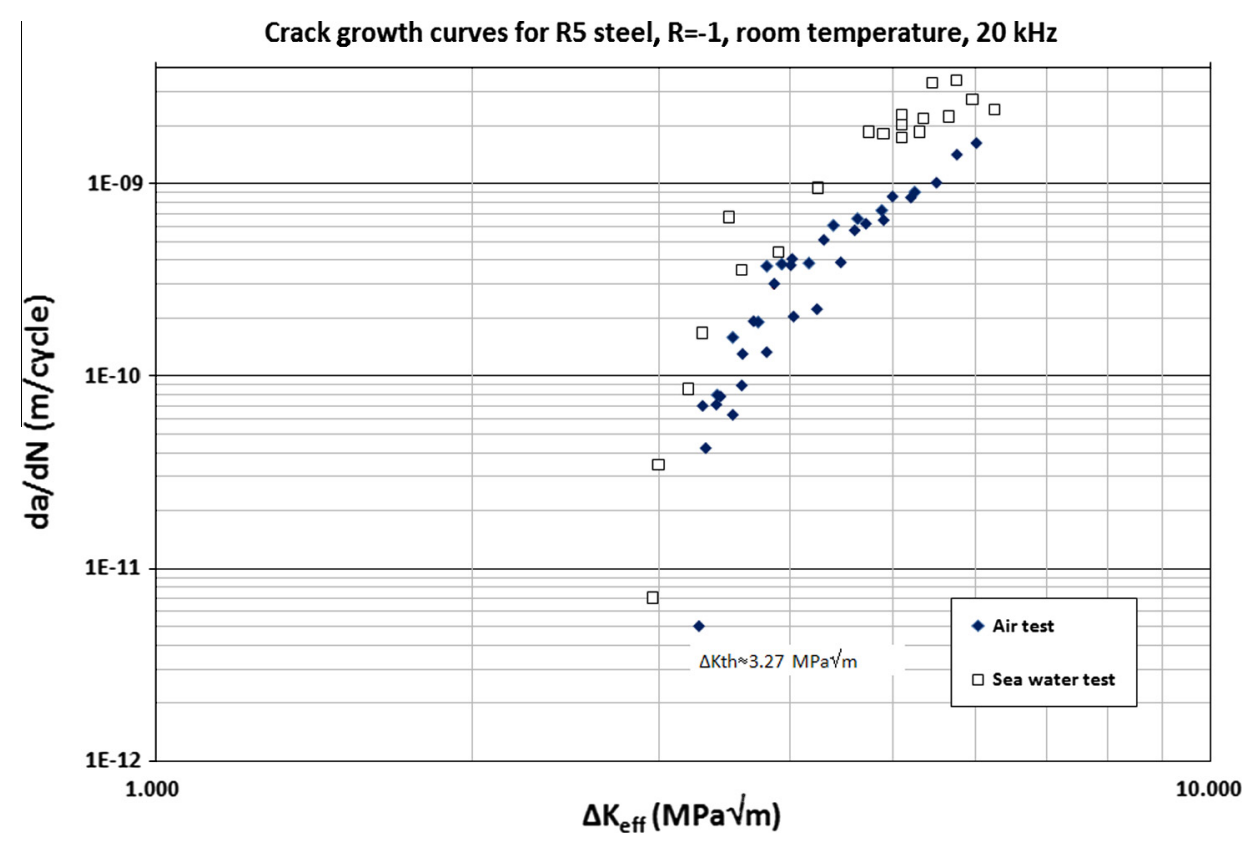

Fig. A1. Experimental $\frac{d a}{d N}=f\left(\Delta K_{\text {eff }}\right)$ curve in mode I for the R5 steel $(R=-1)$, in air and under sea water flow at room temperature.

sea water flow at stress amplitudes between 150 and $350 \mathrm{MPa}$ on the same VHCF specimens but with a polished surface $(R a=0.1 \mu \mathrm{m})$ to investigate a possible roughness effect. There was no evidence of the surface roughness effect under sea water flow (Fig. 4): the fatigue results of specimens with $R a=0.1 \mu \mathrm{m}$ are in the scatter band (standard deviation: $52 \mathrm{MPa}$ ) of the experimental data with $R a=0.6 \mu \mathrm{m}$.

This study shows experimental evidence of the coupling between corrosion and mechanical damage due to cyclic stress, even at $20 \mathrm{kHz}$ while some authors think that corrosion-fatigue interaction is not active when the loading frequency is high because of the long characteristic time of the corrosion process compared with the loading period. The observations of this study tend to show that the number of loading cycles or more exactly the number of reversals $2 \times N$ (not the time) is a key factor in the fatigue crack initiation phenomenon under sea water flow as suggested in [18]. We believe that when the number of reversals is high enough under a given stress amplitude, intrusions-extrusions appear at the surface of the materials. As soon as they appear there is a strong interaction with environment as suggested by Krupp [19]; consequently crack initiation is due to environmentally assisted slip irreversibility.

As some authors have reported [20] the influence of aqueous corrosive solutions on fatigue damaging is generally described in terms of surface dissolution effect or hydrogen reduction reactions (or both). Cyclic strain can enhance local electrochemical reactions which closely depend on plastic deformation [21]. In our study, working at $20 \mathrm{kHz}$ in the elastic regime, plastic deformation is not present at the macroscopic scale but exists at the grain scale. The effect of dissolution occurs when fresh metal is exposed. The point at which pitting occurs at a rate less than that of crack growth is the point when mechanics becomes more dominant than electrochemical dissolution. The reason for this is that the solution chemistry is no longer favorable for dissolution at a rate that exceeds the crack growth rate. Slip irreversibility occurs because there is local plastic deformation due to the strain concentration associated with the pit stress-concentrating feature.

Further investigations should be carried out to deeply understand the physical phenomenon involved in the fatigue damage process assisted by corrosion in VHCF regime. One may imagine ultrasonic fatigue tests with potentiostatic measurements to monitor corrosion current and potential evolution during a fatigue test. However, not immerged experiments (to avoid any cavitation) is a big experimental difficulty for carrying out such tests. Investigation of the corrosion pitting kinetics under cyclic loading is probably a key factor for a better understanding of fatigue corrosion process. In situ micro-tomography under both ultrasonic cyclic loading and sea water corrosion may be an interesting way and challenge for future researches too.

\section{Conclusion and prospects}

Very high cycle fatigue tests were carried out up to $10^{9}$ cycles on smooth specimens in hot rolled martensitic-bainitic steel under three different conditions (i) virgin specimens, (ii) pre-corroded specimens and (iii) under artificial sea water flow during the fatigue test. The fatigue strength at $3 \times 10^{8}$ cycles is significantly reduced by a factor of $74 \%$ compared to the virgin specimens and of $71 \%$ compared to the pre-corroded ones. The poor corrosion-fatigue strength is related to the size of the pits. The assessment of the crack growth shows that crack initiation dominates the total fatigue life when $N>10^{7}$ cycles. During this study a strong coupling between environment and cyclic loading has been proved. Even at ultrasonic frequency, fatigue damage and corrosion pitting are interacting for creating crack initiation at very low stress amplitude corresponding to the absence of fatigue crack initiation under fatigue in air. This has to be more investigated for understanding the physical mechanisms involved in corrosion-fatigue in VHCF regime. Anyway, it has been shown that ultrasonic fatigue tests in conjunction with sea water flowing is a good experimental way to investigate the VHCF strength of steel under corrosion conditions with reasonable test time duration.

\section{Acknowledgements}

The authors acknowledge Prof. José Luis Arana for discussions. They acknowledge Vicinay Cadenas S.A. company for its financial support and both PCP France - Mexico and CONACYT for their financial support too. 


\section{Appendix A}

\section{Annex 1: Experimental crack growth data (see Fig. A1).}

\section{References}

[1] Bathias C, Paris PC. Gigacycle fatigue in mechanical practice. New York USA: Marcel Dekker Publisher Co.; 2005.

[2] Marines I, Bin X, Bathias C. An Understanding of very high cycle fatigue of metals. Int J Fatigue 2003;25:1101-7.

[3] Zuo JH, Wang Z, Han H. Effect of microstructure on ultra-high cycle fatigue behavior of Ti-6Al-4V. Mat Sci Eng A 2008;473:147-52.

[4] Ammar HR, Samuel AM, Samuel FH. Effect of casting imperfections on the fatigue life of 319-F and A356-T6 Al-Si alloys. Mater Sci Eng A 2008;473:65-75.

[5] Pang HT, Reed PAS. Microstructure effects on high temperature fatigue crack initiation and short crack growth in turbine disc nickel-base superalloy Udimet 720 Li. Mater Sci Eng, A 2007:448:67-9.

[6] Yeske RA, Roth LD. Environmental effects on fatigue of stainless steel at very high frequencies. In: Wells (Westinghouse), Buck JM, Tien Roth, editors. Ultrasonic fatigue. New York, USA: The Metallurgical Society of AIME; 1982. p. 365-85.

[7] Ebara R, Yamada Y. Corrosion fatigue behaviour of $13 \mathrm{Cr}$ stainless steel and Ti6Al-4V at ultrasonic frequency. In: Wells (Westinghouse), Buck JM, Tien Roth, editors. Ultrasonic fatigue. New York, USA: The Metallurgical Society of AIME; 1982. p. 349-64.

[8] Paris PC. The relationship of effective stress intensity, elastic modulus and Burgers-vector on fatigue crack growth as associated with fish-eye gigacycle fatigue phenomena, In: Proceedings of VHCF-3, Kyoto, Japan, 2004, p. 1-13.

[9] Marines I, Paris PC, Tada H, Bathias C. Fatigue crack growth from small to long cracks in VHCF with surface initiations. Int J Fatigue 2007;29:2072-8.

[10] Gutman EM, Soloviof G. The mechanochemical behavior of type 316L stainless steel. Corros Sci 1996;38:1141-5.

[11] Pyle T, Rollins V, Howard D. The influence of cyclic plastic strain on the transient dissolution behavior of $18 / 8$ stainless steel in $3.7 \mathrm{M} \mathrm{H}_{2} \mathrm{SO}_{4}$. J Electrochem Soc 1975;122:1445-53.

[12] Palin-Luc T, Perez-Mora R, Bathias C, Dominguez G, Paris PC, Arana JL. Fatigue crack initiation and growth on a steel in the very high cycle fatigue regime with sea water corrosion. Eng Fract Mech 2010;77:1953-62.
[13] Wu TY, Bathias C. Application of fracture mechanics concepts in ultrasonic fatigue. Eng Fract Mech 1994;47:683-90.

[14] Sun (2000); Etude du seuil de fissuration à haute fréquence en fatigue et en fretting fatigue. Ph.D. Thesis, CNAM, Paris France.

[15] Bathias C, Pineau A. Fatigue of materials and structures. ISTE Ltd and John Wiley \& Sons Inc; 2010. p. 512.

[16] Paris PC, Palin-Luc T, Tada H, Saintier, N. Stresses and crack tip stress intensity factors around spherical and cylindrical voids and inclusions of different elastic properties and with misfit sizes, In Proceedings Int. Crack Path, ESIS Ed., Vicenza, Italy; 23-25 September 2009: 485-502.

[17] Stanzl-Tschegg S, Mughrabi H, Schoenbauer B. Life time and cyclic slip of copper in the VHCF regime. Int J Fatigue 2007;29:2050-9.

[18] El May M, Palin-Luc T, Saintier N, Devos O. Effect of corrosion on the high cycle fatigue strength of martensitic stainless steel X12CrNiMoV12-3. Int J Fatigue 2013;47:330-9.

[19] Krupp U. Fatigue crack propagation in metals and alloys. Weinheim: WileyVHC Verlag GmbH \& Co.; 2007. ISBN: 978-3-527-31537-6.

[20] Magnin T, Lardon JM. The influence of a $3.5 \% \mathrm{NaCl}$ solution on the fatigue damage evolution in a planar slip f.c.c. stainless steel. Mater Sci Eng 1985;76:7-10.

[21] Patel C. Cyclic strain enhanced dissolution behavior of mild steel in 10 pct $\mathrm{NH}_{4} \mathrm{NO}_{3}$ and the correlation with corrosion fatigue properties. Metall Trans A 1980;11:301-6.

[22] Halidun-Kelestmur M, Chaki T. The effect of various atmospheres on the threshold fatigue crack growth behavior of AISI 304 stainless steel. Int J Fatigue 2001;23:169-74.

[23] Steinbock J, Gudladt H-J. More insights into fatigue crack growth from experiments on steels and aluminium alloys - thresholds. Mater Sci Eng A 2011;528:1296-301.

[24] Tada H, Paris PC, Irwin GR. The stress analysis of cracks handbook. 3rd ed. ASME; 2000 [details in appendix 1].

[25] Bathias C, Paris PC. Gigacycle fatigue of metallic aircraft components. Int J Fatigue 2010;32:894-7.

[26] Murakami Y. Metal Fatigue: Effect of Small Defects and Non-Metallic Inclusions. Elsevier Ed.; 2002.

[27] Hertzberg RW. Deformation and fracture mechanics of engineering materials. New York: John Wiley; 1996.

[28] Paris PC, Tada H, Donald JK. Service load fatigue damage - a historical perspective. Int J Fatigue 1999;21:S35-46. 